\section{Commentary: Outcomes of truncus arteriosus repair: Insights from time and numbers}

\author{
Christoph P. Hornik, MD, PhD, MPH
}

In this issue of the Journal, Dr Naimo and colleagues ${ }^{1}$ share findings from their review of 255 consecutive patients undergoing truncus arteriosus repair at 3 Australian hospitals between 1978 and 2018. The article is remarkable for the size of the patient cohort and the excellent $96 \%$ followup among survivors to a median of 16.4 years. Leveraging this rich dataset, the authors identified important early and late mortality trends and risk factors, including a 1-year mortality of $13.3 \%$, conditional survival past 1 year of $93.5 \%$, and 20 -year survival of $76.8 \%$. Although prior case series, including multicenter reports from the Society of Thoracic Surgeons, have reported outcomes and identified risk factors for patients with truncus arteriosus, cohorts were smaller and duration of follow-up shorter. The value of a larger sample size and longer follow-up may be best illustrated by the reported analysis of neonatal outcomes. Although the proportion of neonatal operations increased over time, mortality remained unchanged and significantly higher than for operations performed outside the neonatal period. Upon closer examination, mortality at 1 and 10 postoperative years was highest among neonates operated on in the first and fourth weeks of life, subgroups that carried the highest prevalence of comorbidities (23/24 neonates operated on in the first week of life) and heart failure symptoms requiring intensive care unit (6/13 neonates operated on in the fourth week of life), respectively. Of note, neither of these were significant risk factors for early and late mortality when analyzed in the entire patient cohort.

The importance of detailed analyses of risk factors for early and late outcomes in age- and disease-specific subgroups is well understood to clinicians and researchers in

\footnotetext{
From the Department of Pediatrics and Duke Clinical Research Institute, Duke University School of Medicine, Durham, NC.

Disclosures: The author reported no conflicts of interest.

The Journal policy requires editors and reviewers to disclose conflicts of interest and to decline handling or reviewing manuscripts for which they may have a conflict of interest. The editors and reviewers of this article have no conflicts of interest.

Received for publication May 9, 2020; revisions received May 9, 2020; accepted for publication May 11, 2020; available ahead of print May 23, 2020.

Address for reprints: Christoph P. Hornik, MD, PhD, MPH, 301 West Morgan St, Durham, NC 27701 (E-mail: christoph.hornik@dm.duke.edu).

J Thorac Cardiovasc Surg 2021;161:241-2

$0022-5223 / \$ 36.00$

Copyright (c) 2020 by The American Association for Thoracic Surgery

https://doi.org/10.1016/j.jtcvs.2020.05.025
}

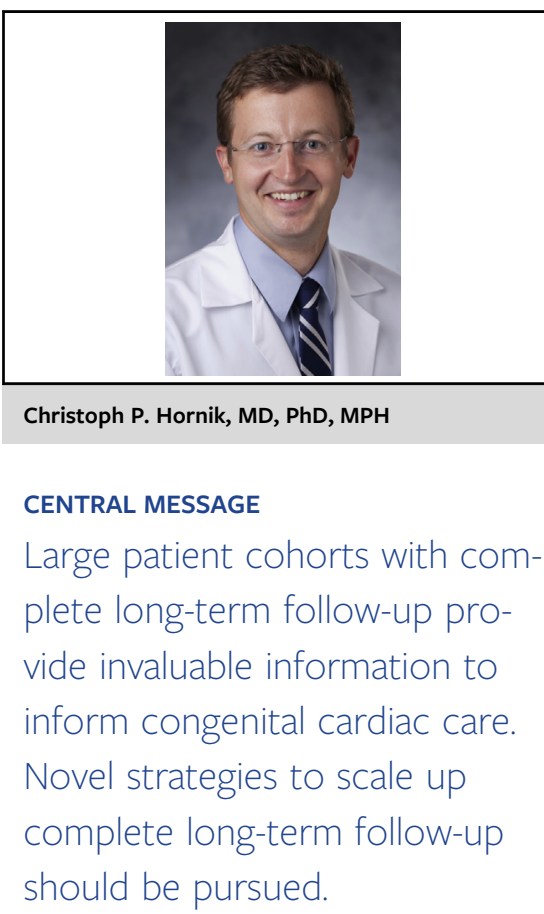

congenital heart disease. The challenge lies mostly in acquiring data to conduct detailed analyses. Registries, including efforts from the Society of Thoracic Surgeons and the Congenital Heart Surgeons Society, have generated vast amounts of data that identified patient subgroupspecific management strategies for several congenital heart defects, including truncus arteriosus. ${ }^{2-4}$ Although registries will undoubtedly remain invaluable to advancing knowledge in our field, alternative data-collection strategies, especially those that permit longitudinal follow-up across institutions, should be pursued. After widespread implementation of the electronic health record (EHR), tools that facilitate access, use, and sharing of EHR data, most notably based on Health Level 7 Fast Healthcare Interoperability Resources standards, are increasingly applied. ${ }^{5}$ Although Fast Healthcare Interoperability Resources offers several strategies to unlock to power of EHR data through Application Programming Interfaces, the development of the personal health record, maintained by patients over their life span and across institutions, may be of particular value. ${ }^{6}$ Recruiting patients into large-scale efforts to share personal EHR data may transform our ability to directly understand short- and long-term impacts of congenital cardiac care for patients as they transition across healthcare systems over their lifetime. Although complex, personal EHR datasharing efforts may help make large and long-term studies such as the one by Naimo and colleagues ${ }^{1}$ more commonplace in congenital heart care. 


\section{References}

1. Naimo PS, Bell D, Fricke TA, d'Udekem Y, Brizard CP, Alphonso N, et al. Truncus arteriosus repair: a 40-year multicentre perspective. J Thorac Cardiovasc Surg. 2021;161:230-40.

2. Jacobs JP, O’Brien SM, Pasquali SK, Jacobs ML, Lacour-Gayet FG, Tchervenkov CI, et al. Variation in outcomes for benchmark operations: an analysis of the Society of Thoracic Surgeons congenital heart surgery database. Ann Thorac Surg. 2011;92:2184-92.

3. Konstantinov IE, Karamlou T, Blackstone EH, Mosca RS, Lofland GK, Caldarone CA, et al. Truncus arteriosus associated with interrupted aortic arch in 50 neonates: a Congenital Heart Surgeons Society study. Ann Thorac Surg 2006;81:214-22.

4. Russell HM, Pasquali SK, Jacobs JP, Jacobs ML, O'Brien SM, Mavroudis C, et al Outcomes of repair of common arterial trunk with truncal valve surgery: a review of the society of thoracic surgeons congenital heart surgery database. Ann Thorac Surg. 2012;93:164-9.

5. Braunstein ML. Healthcare in the age of interoperability: the promise of fast healthcare interoperability resources. IEEE Pulse. 2018;9:24-7.

6. Braunstein ML. Health Care in the age of interoperability part 5: the personal health record. IEEE Pulse. 2019;10:19-23.
See Article page 230.

\section{Commentary: Truncus among us}

\author{
Christopher E. Mascio, MD
}

The first complete repair of truncus arteriosus (TA) was performed in 1962 by Sloan, but not published until 1974 by Behrendt and colleagues ${ }^{1}$ as part of a larger cohort of patients. Ebert and colleagues ${ }^{2,3}$ published a series of complete repair of TA in both 1976 and 1984 on infants aged 6 months or less and reported an operative mortality of $11 \%$ to $20 \%$. Because the patients were a few months of age or older, not surprisingly, the most common cause of mortality was pulmonary hypertension. Because of weight loss and congestive heart failure in addition to pulmonary hypertension, Bove and colleagues ${ }^{4}$ advocated and reported success repairing TA in the neonate in 1989.

Naimo and colleagues ${ }^{5}$ present a 40 -year perspective on TA repair in Australia at multiple centers. There are interesting findings that contradict conventional wisdom about preoperative TA physiology and timing of operation among other things. The authors report a neonatal

From the Division of Pediatric Cardiothoracic Surgery, Children's Hospital of Philadelphia, Perelman School of Medicine, University of Pennsylvania, Philadelphia, $\mathrm{Pa}$.

Disclosures: Dr Mascio is a clinical consultant for HeartWare/Medtronic.

The Journal policy requires editors and reviewers to disclose conflicts of interest and to decline handling or reviewing manuscripts for which they may have a conflict of interest. The editors and reviewers of this article have no conflicts of interest.

Received for publication May 12, 2020; revisions received May 12, 2020; accepted for publication May 12, 2020; available ahead of print May 30, 2020.

Address for reprints: Christopher E. Mascio, MD, Pediatric Cardiothoracic Surgery, Children's Hospital of Philadelphia, Perelman School of Medicine, University of Pennsylvania, 3401 Civic Center Boulevard - M875, Philadelphia, PA 19104 (E-mail: mascioc1@email.chop.edu).

J Thorac Cardiovasc Surg 2021;161:242-3 $0022-5223 / \$ 36.00$

Copyright $(9) 2020$ Published by Elsevier Inc. on behalf of The American Association for Thoracic Surgery

https://doi.org/10.1016/j.jtcvs.2020.05.050
Check for updates

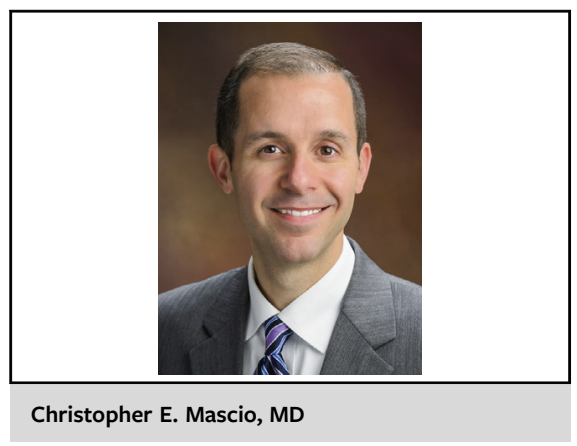

CENTRAL MESSAGE

TA has been repaired success-

fully in the neonate for 30 years.

Advances in imaging, operative

techniques, and perioperative

care have contributed to

improving morbidity and

mortality. mortality of $23.7 \%$ compared with $7.4 \%$ in older patients. More specifically, they state that neonates in week 1 of life (because of concomitant anomalies like truncal insufficiency, arch obstruction, and coronary anomalies) and week 4 of life (because of congestive heart failure/pulmonary over circulation) had the worst neonatal outcomes. Only $53 \%$ of those undergoing TA repair in the most recent era (1999-2018) had the operation during the neonatal period. Their mortality and timing of operation are contrasted with the North American approach to TA. Today, it is standard of care to repair TA in the first week of life. The Society of Thoracic Surgeons Congenital Heart Surgery Database reports a mortality for TA of $9.5 \%$ (interquartile range, $0.0 \%-15.4 \%$ ). ${ }^{6}$ 